\title{
Effects of Educational Intervention Programmes on Reproductive Health-Behavioural Intentions among Sickle-Cell Disease Population in South-West Nigeria
}

\author{
Article by Oyeneye, Elizabeth. $\mathrm{O}^{1},{ }^{2}$ Nnodimele O. Atulomah \\ ${ }^{1}$ Department of Public Health, Texila American University, Guyana, South America. \\ ${ }^{2}$ Department of Public Health, Babcock University, Ilishan, Nigeria \\ E-mail: foyeneye@yahoo.co.uk $k^{1}$ atulomahn@babcock.edu.ng ${ }^{2}$
}

\begin{abstract}
Youths with Sickle Cell Disease (SCD) are sexually active and at higher risk of uncertain reproductive health outcomes because of their health status. This study was a theory-grounded quasi-experimental design to evaluate the effects of two Reproductive Health-Information (RHI) Education intervention programmes with counseling among youths with SCD in South-west Nigeria.

Seventy five participants were purposively assigned to control $(C G)$ and two intervention groups that were randomly selected. All groups completed pretest of Behavioural-Intentions (BI) measures by questionnaire, however, only intervention group one (IG-1) received Reproductive Health-Information (RHI) Education while intervention group two (IG-2) received both (RHI) Education with counseling. At $13^{\text {th }}$ week follow-up, post-test BI was measured for all groups. Data were analyzed using descriptive statistics and ANOVA to compare pre-and post-test measures for all groups at $p=0.05$.

There was no significant difference in measures among the three groups at baseline in respect of RHI (19.16 $\pm 6.61 ; 16.40 \pm 9.35 ; 16.68 \pm 6.31)$, Motivation (15.08 $\pm 4.13 ; 11.88 \pm 5.26 ; 12.80 \pm 3.81)$, Behavioural

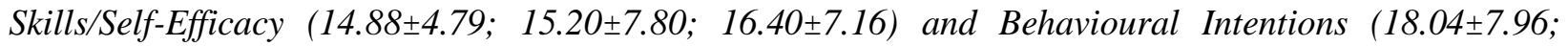
$16.68 \pm 9.04 ; 16.32 \pm 8.04)$ respectively. However, at $13^{\text {th }}$ week follow-up, Intervention group 2

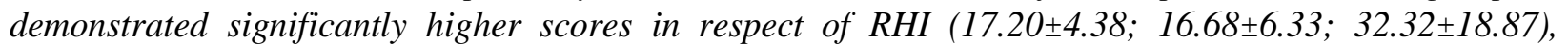

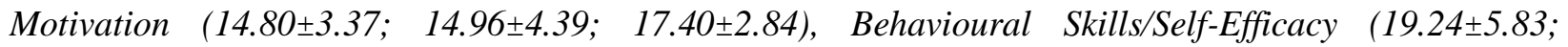
$16.28 \pm 4.74 ; 21.04 \pm 4.95)$ and $B I(18.88 \pm 6.68 ; 23.40 \pm 5.61 ; 26.68 \pm 7.42)$ than Intervention group 1 and Control respectively.

Intervention 2 combining RHI -Education with counseling had the most significant impact on youth reproductive health behavioural-Intentions. It is therefore recommended that reproductive health information for the SC youths should strategically be accompanied with counseling to achieve behavioural change.
\end{abstract}

Keywords: Reproductive Health, Information, Motivation, Behaviour, Behavioural Intentions, Sickle Cell youths.

\section{Introduction}

Reproductive health considers issues of well-being of women and men in terms of processes involving developing sexual identity, pre-conception care, pregnancy, birth and their related conditions, and prevention of associated diseases and illnesses. Many youths do not have adequate access to reproductive health information from reliable sources. Youths with Sickle Cell Disease (SCD) are sexually active and at higher risk of uncertain reproductive health outcomes because of their health status. Nigeria has estimated population of $186,053,386$ with $42.79 \%$ of age $0-14$ years and $19.48 \%$ of age $15-24$ years as at January 2017 (CIA world fact book, 2017). Sickle cell prevalence and burden in Nigeria is increasing (WHO, 2012). Prevention and management of sickle cell disease has improved lifespan of patients with sickle cell anaemia and it has been reported that about fifty per cent of them survive beyond the fifth decade of life (Platt, Brambilla, Rosse, Milner, Castro, Steinberg, and Klug, 1994). They now live longer enough to consider issues of reproductive health. Youth generally, including those living with sickle cell 
disorder, are sexually active, explorative, can engage in unsafe sexual relationships with more than one partner and at risk of STDs/HIV/AIDS. Confidence to initiate parenting plan in relation to sexual and reproductive health issues may be affected by the fear of the unknown about their health status. Some of them in a bid to explore their sexuality may become involved in unsafe sexual practices that may predispose them to unintended pregnancy and associated attendant risks.

Because of the urgent need to address the persistent poor reproductive health outcomes of adolescents globally and particularly in low and middle income communities, there is need to gain more understanding regarding their behavioural intentions through assessment of important antecedents such as their level of reproductive health knowledge, motivational characteristics and behavioural skills. Parenting plan involves initiation of marriage and sexual relationship, confidence to plan pregnancy, prevention of risky behaviours and demonstration of sexual refusal/negotiating skills. Access to welldesigned reproductive health information and reinforcement through targeted counselling can improve sexual and reproductive health behaviour of the youth through developing self-efficacy skills and confidence to prevent risky behaviour that would impact on their intentions to initiate adequate parenting plan. Health- risk behaviour among youth includes sexual and reproductive health behaviour that contributes to unintended pregnancy and sexually transmitted infections (STIs) including human immunodeficiency virus (HIV) infection. (Grunbaum, Kann, Kinchen, Ross, Hawkins, Lowry, et al 2004 and Envuladu, Anke, Zwanikken and Zoakah, 2017). Previous studies have demonstrated limited knowledge regarding sexual health among youths in Nigeria, Ghana and Ethiopia Housten, Abel, Dadekian, and King, 2015; Abiodun, Abiodun, Ani and Sotunsa, 2016; Abajobir, \& Seme, 2014) and Aninanya, Debpuur, Awine, Williams, Hodgson \& Howard, 2015). The understanding of the reproductive experiences in people with SCD was enhanced by an educational intervention (Gallo, Wilkie, Suarez, Labotka, Molokie, Thompson \&Johnson, 2010).

Behavioural interventions based on tested theoretical frameworks are known to achieve better outcome than interventions that lack conceptual grounding in behaviour theory. There is paucity of literature and research on reproductive health information with respect to parenting- plan decisions among youth living with sickle cell disorder. Educational interventions designed with motivational package that provides information about reproductive health options and consequences characterized by reinforcement from counseling that support and motivate people living with sickle cell disease to identify, initiate and implement an informed parenting plan are few in the literature. This study was based on Information, Motivation and Behavioural skill (IMB) Model, which attempt to explain the dynamics involved in playing out behaviour in risk exposure situation. It has been reported that the outcome of the impact intervention designed based on the IMB model persisted up to 12 months follow up (Chang, Choi, Kim, and Song, 2014). The model has been well applied in STDs, HIV, and diabetes, tuberculosis studies with promising outcome of behavioural change (Jaworski and Carey, 2001; Singh, 2003; Walsh, Senn, ScottSheldon, Vanable, and Carey, 2011; Ybarra, Korchmaros, Kiwanuka, Bangsberg and Bull, 2013; Ybarra, Korchmaros, Kiwanuka, Bangsberg and Bull, 2013; Raphael, Butler, Rattler, Kowalkowski, Mueller and Giordano, 2013; Saad, Lekhraj, Sabitu, AbdulRahman, AbuSamah, and Ibrahim, 2012; Fisher, Fisher \& Harman, 2003). The IMB model suggests that behaviour would be effectively influenced if motivation accompanies information dissemination. Therefore, this study focuses on the component of the model which recognizes the role of motivation posited would influence behaviour change through improved behavioural skills in the presence of targeted motivational counselling technique

By designing a study to establish proof of concept in the model, the study hypothesizes that individuals who are well informed, well-motivated and perceive themselves as capable of adequately demonstrating behavioural skills self-efficacy will successfully initiate safe parenting plan. Thus, the outcome measures of behaviour intentions for the experimental group two will be significantly different from that measured for control and the experimental group one receiving only the (RHIL) self-study package.

This study which was designed based on the IMB model is needed among the youth of sickle cell clubs in Abeokuta, Ogun state because they are at risk of unfavourable reproductive health outcome consequent 
upon the fact that they are sexually active and may have multiple sexual partners. There is need to achieve improved behavioural intentions of initiating parenting plan among them. It is significant because findings from the study would provide understanding of how the youth with sickle cell can achieve improved behavioural intentions to initiate parenting plan. The Government, sickle cell patients and their parents, Non-Governmental Organisations (NGO's), and other stakeholders may also make use of the report of the study to plan appropriate health promotion and education intervention.

The objective of this study was to evaluate the effects of two Reproductive Health-Information (RHI) Education intervention programmes with counseling on Behavioural Intentions based on the InformationMotivation-Behavioural skills model among youths with SCD in South-west Nigeria.

\section{Methods}

This study was a theory-grounded quasi-experimental design in which twenty five participants were each purposively assigned to control and two intervention groups that were randomly selected. This sample size was derived by considering a confidence level of $95 \%(\mathrm{Za}=1.96), 80 \%$ power $\left(\mathrm{Z}_{\beta}=0.84\right)$ and a minimum difference between baseline and outcome scores of $30 \%$. The two intervention groups were Eko Island sickle cell club, Lagos State as Intervention one (IG-1) and Aglow sickle cell club, Abeokuta, Ogun State as Intervention two (IG-2), while sickle cell club of Ijebuland, Ogun State served as the Control group (CG). A validated 67-item questionnaire based on the IMB model conceptual domains of information, motivation, behavioural skills self-efficacy and behavioural intentions to initiate parenting plan was developed to measure primary outcomes of level of Information about RHI measured on 65point rating scale, Motivation and Behavioural Skills/Self-Efficacy to make reproductive health decisions on 30-point and Behavioural intentions to initiate parenting plan measured on a 36-point rating scale respectively. All groups completed pretest Behavioural-Intentions (BI) measures (questionnaire) at baseline, however, only IG-1 received Reproductive Health-Information (RHI) Education while IG-2 received both RHI- Education with counseling. The two interventions were Reproductive HealthInformation Leaflet (RHIL) self-study and combined RHIL-Reproductive Health Educational and Behavioural (RHEB) Package with motivational counseling to reinforce contents of the RHIL related to adolescent reproductive health implemented for four weeks. At 13th week follow-up, post-test BI was measured for all groups. The research was approved by the ethical committee of State Hospital Abeokuta, Ogun State, Nigeria. Informed consent was obtained from all respondents and the Sickle Cell Club executives before the commencement of the study. The data collected were coded manually and analyzed with Statistical Package for Social Sciences (SPSS) version 22. For descriptive statistics and ANOVA to compare pre- and post-test measures for all groups at $\mathrm{p}=0.05$. Cohen's $\mathrm{d}$ value for effect size at $95 \%$ confidence interval was computed using the Lenhard \& Lenhard online calculators (Lenhard \& Lenhard, 2016).

\section{Results}

The demographic characteristics of the respondents are presented in table 1 . Respondents were males $(16.0 \% ; 10.7 \% ; 14.7 \%)$ and females $(17.3 \% ; 22.7 \%$; $18.7 \%)$; and their ages were $17.12 \pm 4.23,17.24 \pm 3.09$ and 18.28 \pm 2.81 years for control, Intervention 1 , and Intervention 2 groups respectively. Majority (96.0\%) were from the Yoruba ethnic group. Participants with some form of education $(29.3 \% ; 21.3 \%$; $28.0 \%$ ) for control, Intervention 1, and Intervention 2 groups respectively. 


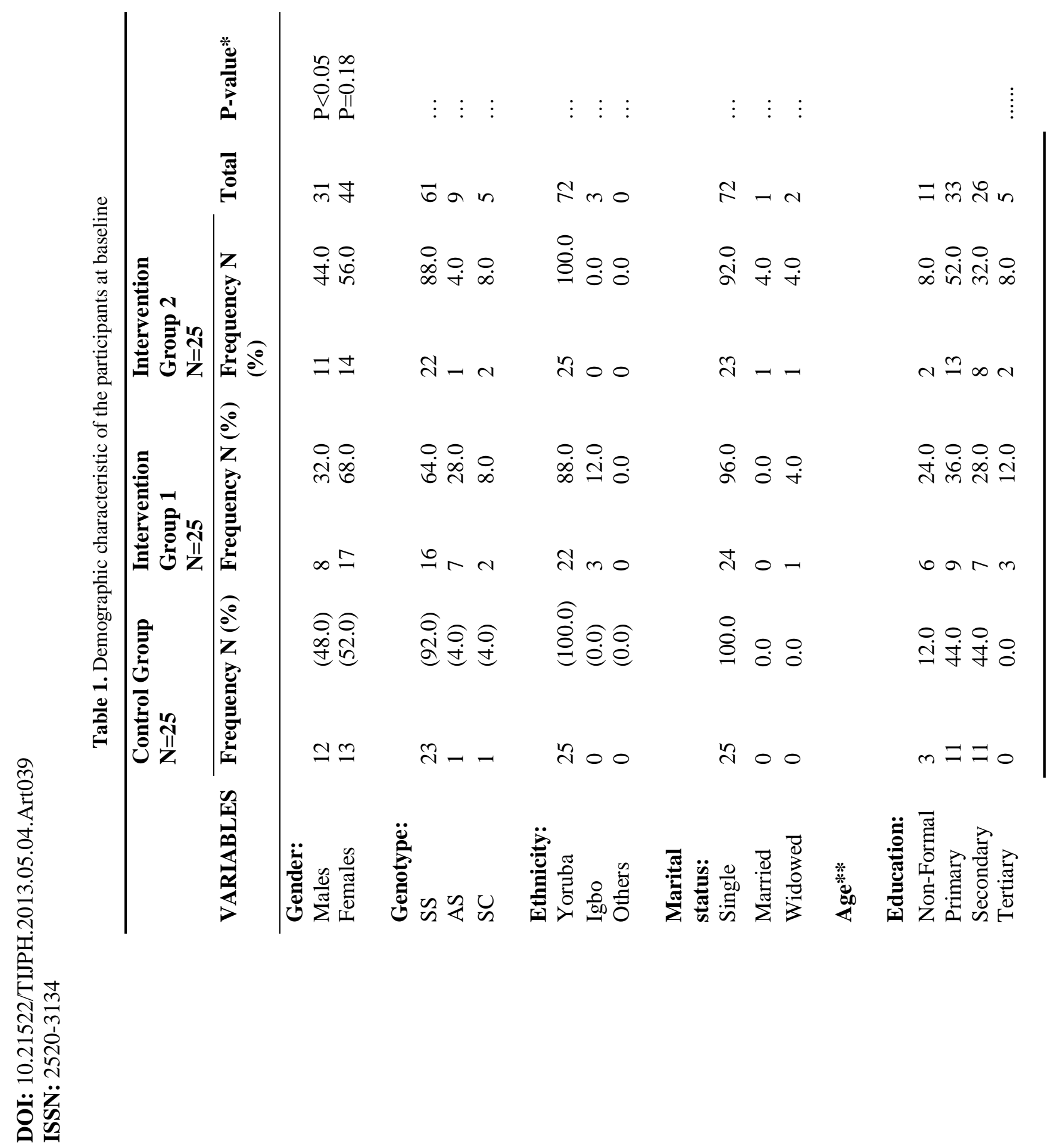




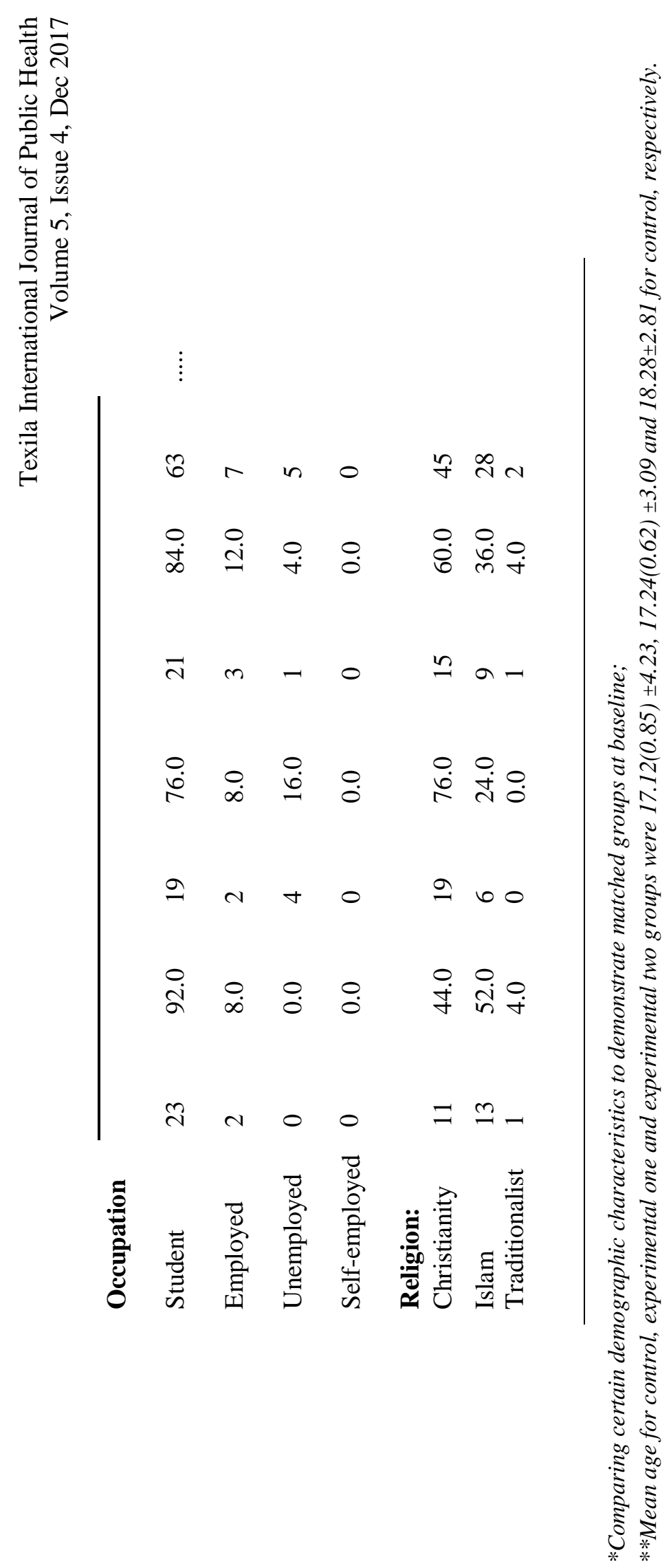


DOI: $10.21522 / \mathrm{TIJPH} .2013 .05 .04 . A r t 039$

ISSN: $2520-3134$

At baseline the mean score of information on reproductive health issues of the respondents was very low, Motivation was generally less than average, Behavioural skills self-efficacy and the behavioural intentions to initiate parenting plan was about average. Also there were no significant differences in measures among the three groups in respect of Information, $(19.16 \pm 6.61 ; 16.40 \pm 9.35 ; 16.68 \pm 6.31)$, Motivation (15.08 $\pm 4.13 ; 11.88 \pm 5.26 ; 12.80 \pm 3.81)$, Behavioural Skills/Self-Efficacy (14.88 \pm 4.79 ; $15.20 \pm 7.80 ; 16.40 \pm 7.16)$ and behavioural intentions to initiate parenting plan $(18.04 \pm 7.96 ; 16.68 \pm 9.04$; $16.32 \pm 8.04$ )values respectively (See Table 2 ). 


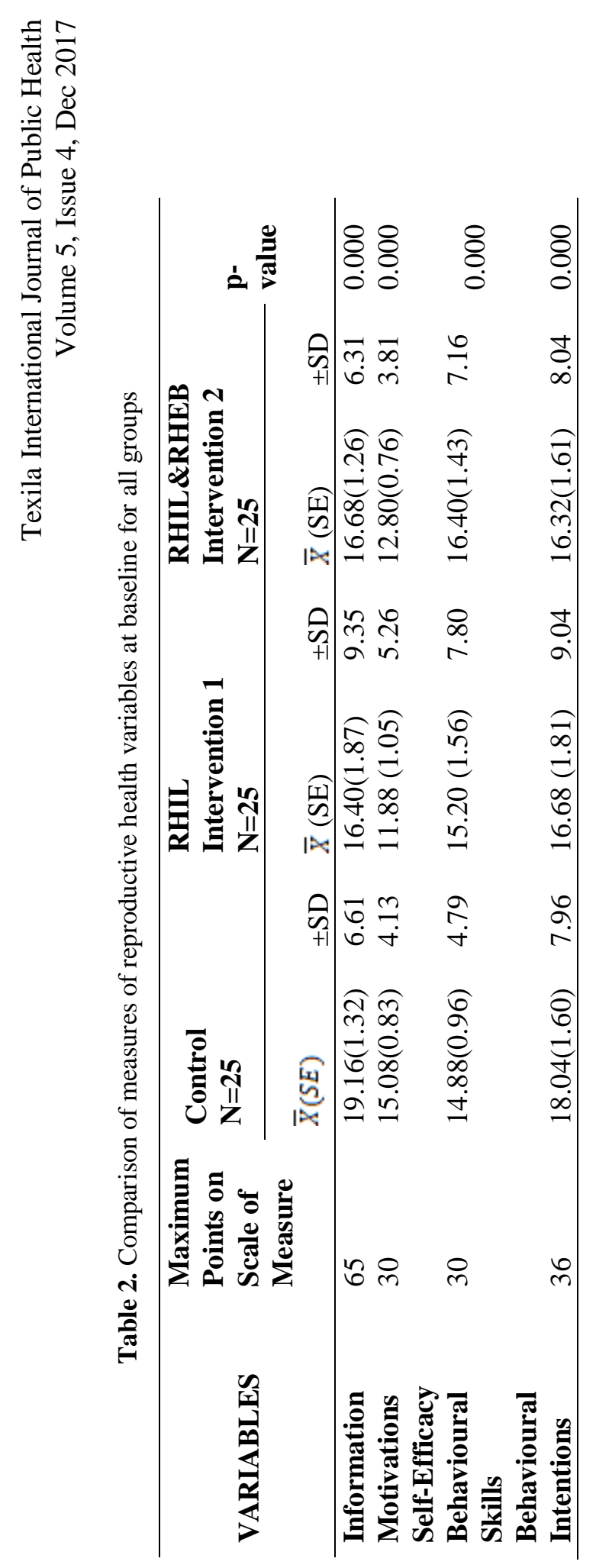


DOI: $10.21522 /$ TIJPH.2013.05.04.Art039

ISSN: $2520-3134$

However, at 13th week follow-up, Intervention 2 demonstrated significantly higher scores in respect of

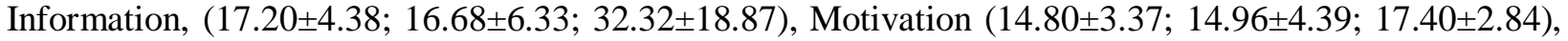
Behavioural Skills/Self-Efficacy $(19.24 \pm 5.83 ; 16.28 \pm 4.74 ; 21.04 \pm 4.95)$, and behavioural intentions to initiate parenting plan $(18.88 \pm 6.68 ; 23.40 \pm 5.61 ; 26.68 \pm 7.42)$ values respectively (See Table 3 ). 


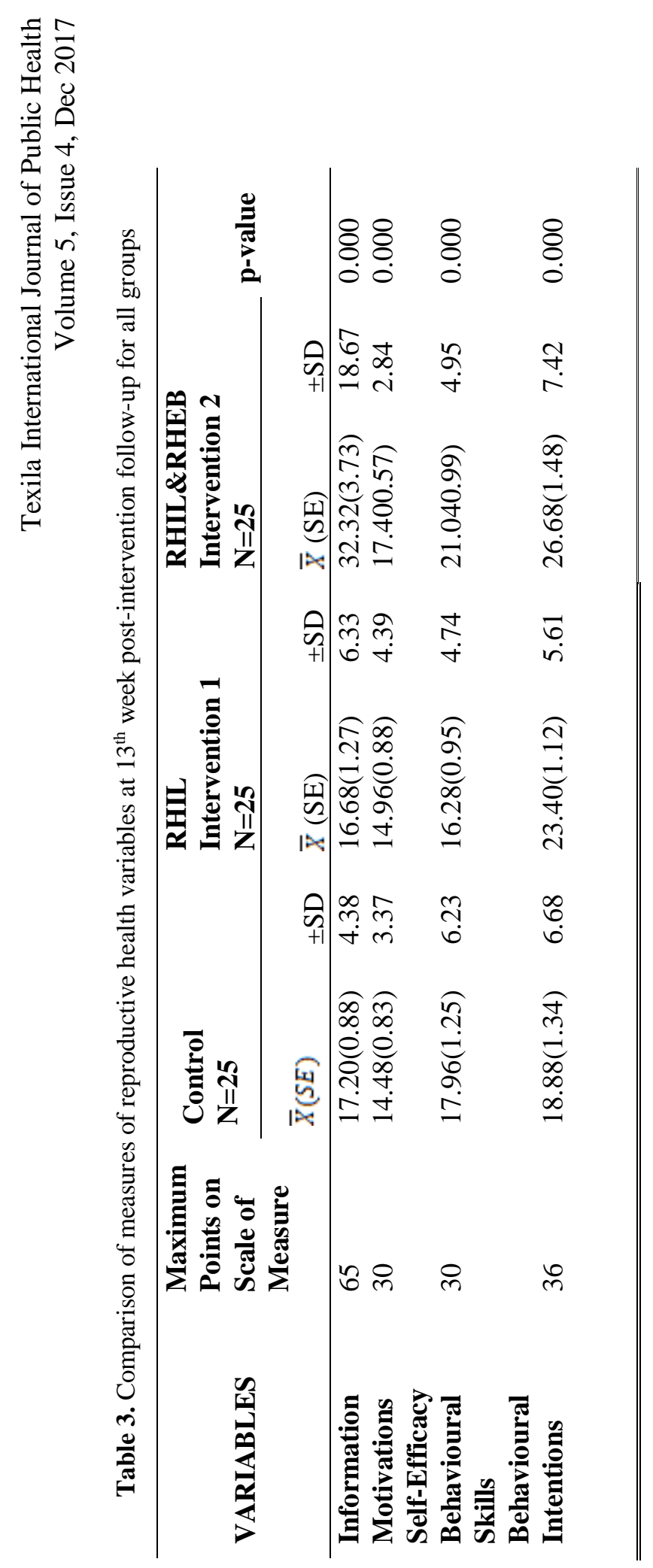


DOI: $10.21522 / \mathrm{TIJPH} .2013 .05 .04 . A r t 039$

ISSN: $2520-3134$

\section{Evaluation of the impact of intervention at 13th week follow-up}

Comparing the variables values obtained at baseline and at $13^{\text {th }}$ week post-intervention follow-up for the control group, there was a reduction in the mean score of information on reproductive health issues, barely no difference in the mean score of motivation factors regarding reproductive health and behavioural intentions to initiate parenting plan, but there was a slight increase in the mean score of behavioural skills and self-efficacy to initiate parenting plan by the respondents. For intervention group one, there was an appreciable increase in behavioural intentions to initiate parenting plan by the respondents, while there was barely any difference in the mean score of information on reproductive health issues and behavioural skills and self-efficacy to initiate parenting plan.For the intervention group two, there was a general appreciable increase in all the variables measured (that is the mean score of information on reproductive health issues, motivation factors regarding reproductive health, behavioural skills and self-efficacy to initiate parenting plan and behavioural intentions to initiate parenting plan) (See Table 2 and 3 )

\section{Test of hypotheses}

The study proposed a hypothesis that the outcome measures of the experimental group will be significantly different from the control group. That is, information coupled with support and motivation on reproductive health for people living with sickle cell disease will be more effective than information alone to initiate parenting plan by the respondents and much more effective than the control that did not receive any information. The mean score of information on reproductive health issues, motivation factors regarding reproductive health, behavioural skills and self-efficacy to initiate parenting plan and behavioural intentions to initiate parenting plan by the respondents at $13^{\text {th }}$ week post-intervention followup for the intervention group two were generally appreciably higher than that of intervention group one. (See Table 5) In order to determine which of the intervention is more effective, Cohen's d effect size was calculated to determine the magnitude of the effect of the intervention and its significance at $95 \%$ confidence interval. The Cohen's d value for intervention 2 produced large effect for information, motivation and behavioural intentions and intermediate effect for behavioural skills and self-efficacy at $13^{\text {th }}$ week post-intervention follow-up. (See Table 5)

Table 5. Evaluation of interventions one and two for all variables at $13^{\text {th }}$ week follow-up

\begin{tabular}{|c|c|c|c|c|c|c|}
\hline \multirow[b]{2}{*}{ VARIABLES } & \multicolumn{3}{|c|}{$\begin{array}{l}\text { Intervention } 1 \\
\mathrm{~N}=\mathbf{2 5}\end{array}$} & \multicolumn{2}{|c|}{$\begin{array}{l}\text { Intervention } 2 \\
\mathrm{~N}=25\end{array}$} & \multirow[b]{2}{*}{$\begin{array}{l}\text { Cohen's d at } \\
\mathbf{9 5 \%} \text { CI }\end{array}$} \\
\hline & $\frac{\mathbf{N}=\mathbf{2 5}}{X(S E)}$ & $\pm \mathrm{SD}$ & $\begin{array}{l}\text { Cohen's d at } \\
\text { 95\% CI }\end{array}$ & $\begin{array}{l}\mathbf{N}=\mathbf{2 5} \\
\bar{X}(\mathrm{SE})\end{array}$ & $\pm \mathrm{SD}$ & \\
\hline $\begin{array}{l}\text { Reproductive } \\
\text { Health } \\
\text { Information }\end{array}$ & $16.68(1.27)$ & 6.33 & $\begin{array}{l}-0.096(-0.65- \\
0.46)\end{array}$ & $32.32(3.73)$ & 18.67 & $1.115(0.52-1.71)$ \\
\hline Motivation & $14.96(0.88)$ & 4.39 & $0.123(-0.43-0.68)$ & $17.40(0.57)$ & 2.84 & $0.937(0.35-1.52)$ \\
\hline $\begin{array}{l}\text { Behavioural } \\
\text { Skills and } \\
\text { Self-Efficacy }\end{array}$ & $16.28(0.95)$ & 4.74 & $\begin{array}{l}-0.304(-0.86- \\
0.25)\end{array}$ & $21.04(0.99)$ & 4.95 & $0.55(-0.02-1.11)$ \\
\hline $\begin{array}{l}\text { Behavioural } \\
\text { Intentions }\end{array}$ & $23.40(1.12)$ & 5.61 & $0.733((0,16-1.31)$ & $26.68(1.48)$ & 7.42 & $1.105(0.57-1.70)$ \\
\hline
\end{tabular}

Cohen's d intervals interpretation for $\mathrm{r}$. .1 to .3 : small effect; .3 to .5 : intermediate effect; .5 and higher: strong effect (Lenhard \& Lenhard, 2016). 


\section{Discussion}

The findings of this study revealed that the intervention combining Reproductive Health Information Leaflet (RHIL) with Reproductive Health Educational and Behavioural (RHEB) Package (intervention 2) was more effective than Reproductive Health-Information Leaflet (RHIL) self-study alone (intervention one) in influencing Knowledge, behavioural skills and self-efficacy in sexual-risk prevention and behavioural intentions for initiation of parenting plans among the participants, since the Cohen's d value for intervention 2 produced large effect for information, motivation and behavioural intentions and intermediate effect for behavioural skills and self-efficacy at 13thweek post-intervention follow-up.

The mean score of information on reproductive health issues among the respondents in all the groups at baseline was very low; this is consistent with report from other study (Housten, Abel, Dadekian, and King, 2015). At $13^{\text {th }}$ week post-intervention follow-up, the IMB- based intervention two reported increased mean score on information among the experimental group two respondents, while the control and the experimental group one had very slight difference in their mean score. Information provides basic knowledge and awareness about reproductive health. Information usually targets the cognitive domain and supports the change in behavior. This implies that respondents from experimental group two acquired and retained more reproductive health information from both the leaflet and the motivation/counseling sessions, which was absent from the control group. Retention of information over time is necessary in developing reproductive health behaviour and self-efficacy skills which can be achieved better when motivation and counseling sessions are added to the intervention. This result is consistent with report by other studies (Jaworski and Carey, 2001; Singh, 2003; Ybarra, et al, 2013; Bodenheimer, 2005; Ryan, 2009; Wang et al, 2013; Shahine et al, 2015; and Seif, Kohi, and Mselle, 2016).

Majority of the respondents received reproductive health information all the time from their parent and the family planning clinic (a more reliable source of information) was the least accessed. This may be due to the fact that respondents are closer to their parent's because of their health condition and care received from their parent from childhood. Creating awareness on family planning clinic services among the youth will improve access to the services.

The appreciable increase in the mean score of motivation factors regarding reproductive health at 13th week post-intervention follow-up among the experimental group two was due to the motivation/counseling session that was applied to each participant. This is because the affective domain of the respondents received the appeal from the motivation/counseling sessions and was encouraged to develop a favorable attitude towards the prescribed reproductive health behaviour. The respondents received motivation by considering their personal attitudes towards the reproductive health behaviour and perceived social support from their parents, religious leaders and the significant others in their life for the reproductive health behaviour. Their subjective norm or perception of how others, especially their partner might behave or feel about their reproductive health behaviour was also responsible for the increased motivation. The control and experimental group one did not have access to this counseling session during the study. This result is consistent with report by other studies (Singh, 2003 and Raphael, Butler, Rattler, Kowalkowski, Mueller, and Giordano, 2013)

The mean score of behavioural skills and self-efficacy to initiate parenting plan increased most appreciably among the respondents in experimental group two at $13^{\text {th }}$ week post-intervention follow up because of the interplay and additional effect of information and motivation/counseling sessions experienced by the respondents in this group which was absent in the control and the other group. This suggests that motivation is a stronger predictor of self-efficacy skills which is responsible for the reproductive health behavior. Behaviour addresses the psychomotor domain with practice of the expected activity that will lead to the favourable outcome. Behavioral skills are enhanced by self-efficacy skills, which is the confidence in the ability to behave in a prescribed manner. Information about the behaviour and motivation to do the activity is necessary to develop the behavioural skills. In practice a better motivated youth living with sickle cell disorder that have access to reliable reproductive health information will develop better reproductive health self-efficacy skills and will have better reproductive 
DOI: $10.21522 / \mathrm{TIJPH} .2013 .05 .04 . A r t 039$

ISSN: $2520-3134$

health behaviour. This observation is consistent with report from other studies (Jaworski and Carey, 2001; Singh, 2003; Walsh, Senn, Scott-Sheldon Lori, Carey, 2011; Fisher, Fisher, and Harman, 2003; Zhu, Cai, Ma, Li, Zhu, He, Redmon, and Qiao, 2013); Jungling, Jingli, Yaocheng and Jinming, 2013; and Fisher, 2012)

The main outcome measure was behavioural intention to initiate parenting plan measured by the extent of confidence and intention to negotiate reproductive health and sexual relationship. The mean score of behavioural intentions to initiate parenting plan of the respondents at baseline increased appreciably at 13th week post-intervention follow-up in the experimental group two. The increase can be due to the effect of the motivation and counseling sessions added to the information in the leaflet provided for the respondents in this group. Retention of information over time and motivation achieved better development of reproductive health behaviour and self-efficacy skills. This result is consistent with report from other studies (Bodenheimer, 2005; Ryan, 2009; Jaworski and Carey, 2001; Singh, 2003; Wang et al, 2013; Ybarra, et al 2013; Shahine et al, 2015; Seif, Kohi, and Mselle, 2016; Osborn and Egede, 2009).

Unintended pregnancies, sexually transmitted diseases can be prevented and safer sex practice can be achieved if the youth have access to reliable reproductive health information and are motivated to take responsibility and behave better

The Cohen's d value at $95 \%$ confidence interval for intervention two produced the largest effect size for information, motivation and behavioural intentions and intermediate effect for behavioural skills and self-efficacy at $13^{\text {th }}$ week post-intervention follow-up. This supports the hypothesis that the primary outcome measures of the intervention group two is significantly different from the control group that received only the leaflets. In other words, reproductive health information combined with support and motivation for youths living with sickle cell disease will be more effective than information giving alone to develop behavioural-skills in sexual-risk prevention and consequently safe reproductive-health intentions to initiate parenting plan by the respondents. The findings from the study showed that intervention two which had the combination of the RHI -Education with counseling had the most significant impact on adolescent reproductive health behaviour. The study result has provided validity for the IMB model theoretical and conceptual framework that guided the study.

\section{Contribution to knowledge}

1. Proof of Concept is a strength in this study providing proof that the IMB model works,

2. The quasi-experimental design including control ensured that confounding was reduced,

3. Sample size of 25 per group was adequate because it was computed for both confidence level $\mathrm{Za}=1.96$ and $80 \%$ power for $\mathrm{Zb}$ of 0.84 to give a minimum of 22 .

4. The computation of Cohen's d established the effect size of the impact of the outcome of the more effective intervention package for the sickle cell youth population.

\section{Conclusion}

The level of reproductive health information among youth living with SCD was low at baseline. Educational Intervention 2 combining RHI -Education with counseling had the most significant impact and is more effective than Reproductive Health-Information Leaflet (RHIL) self-study alone in influencing Knowledge, Behavioural skills self -efficacy and behavioural intentions of initiating parenting plans among the youth living with SCD in South-West Nigeria. The Cohen' d value estimated and established a strong effect size of the impact of intervention 2 on the outcome. It is therefore recommended that reproductive health information for the SC youths should strategically be accompanied with counseling to achieve behavioural change.

\section{Recommendations and suggestions for future research}

Subgroup analysis was not possible in this study, future research is needed to explore the predictive power of the IMB model with specific racial/ethnic groups of Nigerian's youth. Youth programs at sickle cell clubs should develop motivation related programs that include content on incentives, social support, 
reinforcements, drive and intention. The designed RHI leaflet can be adopted and used for public enlightenment in the community and sponsored by stakeholders (Government, Nongovernmental organization, religious associations and institution, fathers, mothers, health workers, friends, schools, media and sickle cell clubs). Research to assess the level of reproductive health information among parents generally and parent of children living with sickle cell disorder is recommended. Other factors and variables responsible for development of reproductive health behaviour apart from information and motivation are also recommended for further research.

\section{Implication for practice}

The counselling was performed by the researcher, however, peers, teachers and parent can be trained to do same, by similar modules among youth generally and especially in other sickle cell clubs in other state in Nigeria.

\section{References}

[1]. Abajobir, A. A., \&Seme, A. (2014). Reproductive health knowledge and services utilization among rural adolescents in east Gojjam zone, Ethiopia: a community-based cross-sectional study. BMC Health Services Research, 14, 138. http://doi.org/10.1186/1472-6963-14-138

[2]. Abiodun O, Abiodun OO, Ani F, Sotunsa O (2016) Sexual and Reproductive Health Knowledge and Service Utilization among In-school Rural Adolescents in Nigeria. J AIDS Clin Res 7:576. doi:10.4172/2155-6113.1000576

[3]. Aninanya GA, Debpuur CY, Awine T, Williams JE, Hodgson A, Howard N (2015) Effects of an Adolescent Sexual and Reproductive Health Intervention on Health Service Usage by Young People in Northern Ghana: A Community-Randomised Trial. PLoS ONE 10(4): e0125267. https://doi.org/10.1371/journal.pone.0125267

[4]. Bodenheimer T, Review helping patients improve their health-related behaviors: what system changes do we need? Dis Manag. 2005; 8(5):319-30.

[5]. Cai Y, Wang Y, Zheng Z, Wang J, Yao W, et al. (2013) Predictors of Reducing Sexual and Reproductive Risk Behaviors Based on the Information Motivation-Behavioral Skills (IMB) Model among Unmarried Rural-To-Urban Female Migrants in Shanghai, China. PLoS ONE 8(4): e62787.doi:10.1371/journal.pone.0062787

[6]. Chang, S. J., Choi, S., Kim, S. A. \& Song, M. (2014) Intervention Strategies Based on Information-MotivationBehavioral Skills Model for Health Behaviour Change: A Systematic Review. Asian Nursing Research 8 (3): pp.172-181.

[7]. CIA world fact book, 2017

[8]. Cohen, J. (1988), Statistical Power Analysis for the Behavioral Sciences, 2nd Edition. Hillsdale, N.J.: Lawrence Erlbaum.

[9]. Envuladu, Esther Awazzi, AnkeVan de Kwaak, Zwanikken Prisca, Zoakah Ayuba Ibrahim, (2017). Sexual and Reproductive Health Challenges of Adolescent Males and Females in some Communities of Plateau State Nigeria, International Journal of Psychology and Behavioral Sciences, Vol. 7 No. 2, 2017, pp. 55-60. doi: 10.5923/j.ijpbs.20170702.02.

[10]. Fisher, C.M., (2012). Adapting the Information - Motivation - Behavioral Skills Model: Predicting HIVRelated Sexual Risk among Sexual Minority Youth. Health Educ Behav 2012 39: 290 DOI: 10.1177/1090198111406537

[11]. Fisher, W. A., Fisher, J. D, \& Harman, J. (2003). The Information-Motivation - Behavioral skills model as a general model of health behaviour change: Theoretical approaches to individual - level change .In suls, J. and wallston, k. (Eds.) Social psychological foundations of health (pp. 127 - 153). London: Blackwell publishers.

[12]. Gallo, A. M., Wilkie, D., Suarez, M., Labotka, R., Molokie, R., Thompson, A., Johnson, B. (2010).Reproductive decisions in people with sickle cell disease or sickle cell trait. Western Journal of Nursing Research, 32(8), 1073-1090.

[13]. Grunbaum, J.A., Kann, L., Kinchen, S., Ross, J., Hawkins, J., Lowry, R., Harris, W.A., McManus, T., Chyen, D., Collins, J. (2004) Youth risk behavior surveillance--United States, 2003. Morbidity and Mortality Weekly Report. Surveillance Summaries, 53(2), 1-96. 
DOI: $10.21522 / \mathrm{TIJPH} .2013 .05 .04 . A r t 039$

ISSN: $2520-3134$

[14]. Housten Ashley, Abel Regina A, Dadekian Joyce, \& King Allison Ann (2015); Youth with Sickle Cell Disease: Genetic and Sexual Health Education Needs; American journal of health behaviour 39(6):856-865. DOI: 10.5993/AJHB.39.6.13

[15]. Jaworski Beth C, Carey Michael P, ( 2001); Effects of a brief, theory-based STD-prevention program for female college students Journal of Adolescent Health; Volume 29, Issue 6, December 2001, Pages 417-425. http://dx.doi.org/10.1016/S1054-139X(01)00271-3

[16]. Jungling Gao, Jingli Wang, Yaocheng Zhu and Jinming Yu, (2013): Validation of an Information-MotivationBehavioural skills model of self-care among Chinese adults with type 2diabetes. Biomed Central Public Health 13:100

[17]. Lenhard, W. \& Lenhard, A. (2016).Calculation of Effect Sizes. available: https://www.psychometrica.de/effect_size.html. Bibergau (Germany): Psychometrica. DOI: 10.13140/RG.2.1.3478.4245

[18]. Osborn, C. Y., Amico, K. R., Fisher, W. A., Egede, L. E., \& Fisher, J. D. (2010). An InformationMotivation-Behavioral Skills Analysis of Diet and Exercise Behaviour in Puerto Ricans with Diabetes. Journal of Health Psychology, 15(8), 1201-1213. http://doi.org/10.1177/1359105310364173

[19]. Platt Orah S., Brambilla Donald J., Rosse Wendell F., Milner Paul F., Castro Oswaldo, Steinberg Martin H., and Klug Panpit P. (1994) ; Mortality In Sickle Cell Disease -- Life Expectancy and Risk Factors for Early Death; N Engl J Med 1994; 330:1639-1644 June 9, 1994DOI: 10.1056/NEJM199406093302303

[20]. Raphael J.L, Butler A.M, Rattler T.L, Kowalkowski M.A, Mueller B.U, Giordano T.P, (2013); Parental information, motivation, and adherence behaviors among children with sickle cell disease. Paediatric Blood \& Cancer, 60(7):1204-10.

[21]. Ryan, P. (2009). Integrated Theory of Health Behaviour Change: Background and Intervention Development. Clinical Nurse Specialist CNS, 23(3), 161-172. http://doi.org/10.1097/NUR.0b013e3181a42373

[22]. Saad, A., Lekhraj, R., Sabitu, K.AbdulRahman A.A, AbuSamah, B., Ibrahim. A. ;( 2012) An HIV-STI risk reduction program among undergraduate students at a northern Nigerian university: a randomized controlled field trial Journal of Public Health (2012) 20: 549. doi:10.1007/s10389-012-0491-1

[23]. Seif, S.A., Kohi, T.W. and Mselle, L.T. (2016) Caretaker's Perceptions on Caretaker-Adolescent Communication on Sexual and Reproductive Health in Unguja-Zanzibar: Implication for Intervention. Health, 8, 518-530.

[24]. Singh S. (2003) Study of the effect of information, motivation and behavioural skills (IMB) intervention in changing AIDS risk behaviour in female university students; AIDS Care. 2003 Jan; 15(1):71-76.

[25]. Walsh Jennifer L, Senn Theresa E, Scott-Sheldon Lori A J, Carey Michael P, (2011);Predicting Condom Use Using the Information-Motivation-Behavioral Skills (IMB) Model: A Multivariate Latent Growth Curve Analysis; Annals of Behavioral Medicine 42(2):235-44 June 2011. DOI: 10.1007/s12160-011-9284-y.

[26]. Wang, J., Yan, S., Wang Y., Cai Y., 2013; Evaluation of reproductive health intervention based on IMB model among female migrants in Shanghai; Journal of Shanghai Jiaotong University (Medical Science) 33(3):335-339, DOI: $10.3969 /$ j.issn.1674-8115.2013.03.017.

[27]. World Health Organization, editor. Early marriages, adolescent and young pregnancies: Report by the Secretariat. Geneva: Sixty-Fifth World Health Assembly: provisional agenda item 13.4 A65/132012; Geneva; 2012. [28]. Ybarra Michele L, Korchmaros Josephine, Kiwanuka Julius, Bangsberg David R. and Bull Sheana (2013) Examining the applicability of the IMB model in predicting condom use among sexually active secondary school students in Mbarara, Uganda. AIDS Behaviour 17(3)1116-1128.

[29]. Zhu, C., Cai Y., Ma, J., Li, N., Zhu, J., He, Y., Redmon, P., and Qiao, Y. (2013) Predictors of Intention to Smoke among Junior High School Students in Shanghai, China: An Empirical Test of the Information-MotivationBehavioral Skills (IMB) Model. PLoS ONE, 8(11). 